\title{
Determinants of alcohol drinking and its association with sexual practices among high school students in Addis Ababa, Ethiopia: Cross sectional study
}

\author{
Dawit Teshome, Teferi Gedif* \\ Department of Pharmaceutics and Social Pharmacy, School of Pharmacy, College of Health Sciences, Addis Ababa University, \\ Addis Ababa, Ethiopia; ${ }^{*}$ Corresponding Author: tgedif@gmail.com \\ Received 12 July 2013; revised 15 August 2013; accepted 30 August 2013 \\ Copyright (C) 2013 Dawit Teshome, Teferi Gedif. This is an open access article distributed under the Creative Commons Attribution \\ License, which permits unrestricted use, distribution, and reproduction in any medium, provided the original work is properly cited.
}

\section{ABSTRACT}

Introduction: Alcohol drinking and risky sexual practices have become serious public health problems among teenagers and young adults globally, including many developing countries. The available reports are sparse, especially there is a lack of recent and representative data for high school students in developing countries including Ethiopia. The aim of this study was to estimate the prevalence, identify determinants, and examine the association of alcohol drinking with sexual practices among high school students in Addis Ababa, capital city of Ethiopia. Methods: School-based cross sectional study was conducted from November to December 2010. Multivariate logistic regression analysis was used to determine the association between students' background characteristics and alcohol use, and alcohol use and sexual practices. Results: Among 2551 students surveyed, lifetime and current (past month) alcohol drinking were reported by $1166(45.7 \%)$ and 676 (26.5\%) students, respectively. Having sexual intercourse at least once in their lifetime was reported by $412(16.2 \%)$ with $151(5.9 \%)$ of them being sexually active during a month prior to the survey. Having multiple sexual partners (52.5\%), drinking alcohol before sexual intercourse (26.4\%), and having sexual intercourse without the use of condom (47.3\%) were also common among sexually active students. In adjusted logistic regression model, age (18 and 19 and older), living with 2 parents, getting pocket money, having alcohol drinking friends and attending general secondary school (grade 9 - 10) were positive predictors of current alcohol drinking. Negative predictors of current alcohol drinking were being Protestant Christian and living with relatives or siblings. Conclusion: Alcohol drinking before sexual intercourse was a major problem among high school students in Addis Ababa, Ethiopia. Male gender, older age and higher school grade, friends influence, religious affiliation, living with parents and getting pocket money were significant predictors of current alcohol drinking. Educating about substance use and risky sexual behaviors, engaging students in extracurricular activities and restricting access to alcohol to high school students may help in solution of these problems on a local scale.

Keywords: Alcohol; Sexual Practice; High School; Addis Ababa; Ethiopia

\section{INTRODUCTION}

Current young generation especially in developing countries including Ethiopia is confronting adulthood in a world vastly different from previous generations. HIV/ AIDS, globalization, urbanization, electronic communication, migration, and economic challenges are among the few [1]. More than 1.75 billion of the world's population is young, aged between 10 and 24 years, and oftentimes thought of as healthy group [2]. However, many risk behaviors such as physical inactivity, antisocial and criminal behavior, and hazardous drinking [3] are often initiated during early and late adolescence [4-7].

Harmful alcohol use is also one of the behaviours which departs from the norms, both social and legal, of the larger society and tends to elicit some form of social control responses such as social rejection or even incarceration [8]. Alcohol abuse is a major global contributing 
factor to death, disease, and injury to the drinker. It may also impact others (e.g. family) through the actions of alcohol abusers. Nearly $55 \%$ of the world's population consumes alcohol and 2.5 million people die each year due to the harmful effects of alcohol abuse [5].

Other common problems among regular alcohol drinkers at early age are economic costs, violence, absenteeism (in the workplace and school), early initiation and unprotected sexual intercourse, multiple sexual partners, unwanted pregnancy, and drug experimentation [9-11]. These combined medical, economic, criminal, and social impacts of abuse and addiction to alcohol, nicotine, and illegal substances in US were estimated to be more than half a trillion dollars a year [12]. Similarly, more than 800 million euros was an estimated cost of hospitalization due to alcohol use in Ireland over the five years period (2000 to 2004) [13].

In Ethiopia, the reported prevalence of hazardous drinking and alcohol dependence was $3 \%$ and $1.5 \%$, respectively [14]. Alcohol and khat, a stimulant drug derived from the shrub (Catha edulis) that is native to East Africa, were the most commonly used social drugs in all high school students in Addis Ababa [15]. Studies also reported initiation of alcohol and other drugs use [16,17] and an increase in frequency and quantity of substance use among teenagers and adolescents for both sexes $[18,19]$. These risk behaviors are often associated with increased risk of morbidity and mortality [3].

Overall, the type and preference of alcoholic beverages consumed, the amount and frequency of alcohol consumed per person and occasions vary greatly among different countries and cultures, among different population groups within a given country, and for each population over time [20,21]. Previous studies showed that schools, friends, families, communities, and religious affiliations are significant predictors of alcohol drinking among adolescents [22-27]. Since most high school students in Addis Ababa are within this (adolescent) age group, they are expected to share the same problems.

Therefore, the aim of this study was to estimate the prevalence, identify determinants, and examine association of alcohol drinking with sexual practice among high school students in Addis Ababa. The research findings would help to inform the most feasible and appropriate intervention targeted at adolescents in general and students in particular in order to minimize risks related to alcohol and drugs use.

\section{METHODS}

\subsection{Study Area}

This study was conducted in Addis Ababa high schools. At the time of the study, the projected total population of the city was $3,040,740(1,448,904$ male and $1,591,836$ female) [28]. Nearly one third (27.5\%) of the city population were young (aged 10 - 24) [29]. At the time of the survey, the city had 154 secondary schools (Grade 9 - 12) owned by government, public, private, religious organizations, non-governmental organizations (NGOs), and foreign communities. At 2010/2011 school year, 117,169 students were enrolled in all secondary schools (grade 9 - 12). Among these, 24.1\% students were attending preparatory school (PPS) (grade 11 and 12) and the rest was attending General Secondary School (GSS) (grade 9 and 10) students [30].

\subsection{Study Design and Sampling}

School-based cross-sectional survey was conducted using a piloted self-administered anonymous questionnaire between November and December, 2010. The study population included all grade 10 and 12 regular students, who volunteered and consented to participation and available at the time of data collection in selected high schools. The European School Survey Project on Alcohol and other Drugs (ESPAD) recommends a minimum of 2400 students for school survey [31]. With the assumption of $85 \%$ response rate $(15 \%$ none or inappropriate responses), of the sample included 2760 students selected using multistage cluster sampling. The participating schools were stratified into GSS and PPS based on the education level and then stratified based on ownership as government, private, public and mission owned schools. After that, the sample size of students for each level and type of school was determined based on proportions of the total students at each school. Finally, each school and class was selected using simple random sampling.

\subsection{Data Collection}

The survey questionnaire was prepared based on ESPAD 2007 student core questionnaire [31] and available literature $[11,14,32]$. It has 35 questions divided into three major categories: background characteristics, alcohol use, and sexual practices. The final questionnaire was prepared in Amharic language and piloted in a government and a private school, which were not included in the actual study. After pre-testing, all the necessary modifications were made and data were collected in each class.

\subsection{Variables}

While the dependent variables were alcohol, khat, cigarette, shisha and cannabis use, and sexual practice of high school students, the independent variables were age, sex, religious affiliations, pocket money, friends and family influence, school type and level, availability of alcohol, khat, tobacco, cannabis and availability of venues for using substances in nearby to the residence or 
school.

\subsection{Data Analysis}

Data were entered into Epi-Info 2008 version 3.5.1 and analyzed using SPSS version 16. Multivariate logistic regression model at $95 \%$ confidence interval was used to determine the association between dependent and independent variables.

\subsection{Ethical Considerations}

This study was reviewed and approved by Ethics Review Committee of the School of Pharmacy, Addis Ababa University. In addition, consent was also obtained from each school and the study participants.

\section{RESULTS}

\subsection{Characteristics of the Study Participants}

A total of 2760 students from 11 GSS (grade 9 - 10) and 4 PPS (grade 11 - 12) participated in the study. Completed 2551 (92.4\%) questionnaires were used for data analyses. The mean age was $16.93(\mathrm{SD} \pm 1.35)$ years ranging from 14 to 25 years old. Most of the students were females $(54.8 \%)$, in the age group of 16 to 17 (54.2\%), GSS students (76.1\%), Orthodox Christian (75.3\%), and living with both parents (57.8\%) (Table 1).

\subsection{Prevalence of Alcohol Drinking}

Of surveyed 2551 students, 1155 (45.7\%) reported drinking alcohol at least once in their lifetime (ever use); and $676(26.4 \%)$ of them reported drinking alcohol 30 days (past month) prior to the survey (current users). Both lifetime (57.1\% vs. $33.4 \%$ ) and current prevalence (36.3\% vs. $20.8 \%)$ rates of alcohol drinking were higher among males than females.

Among students, $2.6 \%$ and $1.1 \%$ were lifetime users and current user of all substances (alcohol, khat, tobacco and cannabis), respectively. Using alcohol and khat either concurrently or at different times were the highest among the students with lifetime (13.6\%) and current (6.5\%), followed by alcohol and cigarette $(8.2 \%$ ever user vs. $4.9 \%$ current user) and alcohol, khat and cigarette use $(7.6 \%$ ever user vs. $3.4 \%$ current user) (Table 2).

\subsection{Alcohol Use History}

As approximately $45 \%$ (1166) students reported ever use of alcohol. Of these, $42.9 \%$ started drinking while attending GSS. Starting alcohol drinking in JSS (35.7\%), primary schools ( $\leq$ Grade 6$)(15.9 \%)$ and PPS $(5.5 \%)$ were reported. Beer/draft (37.2\%), wine $(28.8 \%)$, and local beer tella $(26.9 \%)$ were the most commonly con-
Table 1. Socio-demographic characteristics the study participants $(\mathrm{n}=2551)$.

\begin{tabular}{|c|c|}
\hline Variable & $\mathrm{n}(\%)$ \\
\hline \multicolumn{2}{|c|}{ Gender } \\
\hline Male & $1154(45.2)$ \\
\hline Female & $1397(54.8)$ \\
\hline \multicolumn{2}{|c|}{ Age } \\
\hline$\leq 15$ & $334(13.1)$ \\
\hline 16 & $718(28.1)$ \\
\hline 17 & $666(26.1)$ \\
\hline 18 & $545(21.4)$ \\
\hline$\geq 19$ & $288(11.3)$ \\
\hline \multicolumn{2}{|c|}{ Religion } \\
\hline Orthodox Christian & $1922(75.3)$ \\
\hline Muslim & $285(11.2)$ \\
\hline Protestant Christian & $285(11.2)$ \\
\hline Others ${ }^{*}$ & $59(2.3)$ \\
\hline \multicolumn{2}{|c|}{ Marital Status $(\mathrm{n}=2550)$} \\
\hline Never Married & $2534(99.3)$ \\
\hline Married/Divorced & $16(0.7)$ \\
\hline \multicolumn{2}{|c|}{ Live with $(\mathrm{n}=2007)$} \\
\hline Both parents & $1477(57.8)$ \\
\hline Single parent & $530(20.8)$ \\
\hline Guardian/Orphan centre & $40(1.6)$ \\
\hline Relatives or siblings & $431(17.0)$ \\
\hline Alone & $61(2.4)$ \\
\hline Others ${ }^{\#}$ & $9(0.4)$ \\
\hline \multicolumn{2}{|c|}{ Class level of education } \\
\hline PPS & $611(24)$ \\
\hline GSS & $1940(76)$ \\
\hline
\end{tabular}

"Jehovah witness, pagan/atheist, Catholic Christian, ${ }^{*}$ living with husband/ wife, employer.

Table 2. Prevalence of multiple substance use among the study participants $(\mathrm{n}=2551)$.

\begin{tabular}{lcc}
\hline \multicolumn{1}{c}{ Substance used } & $\begin{array}{c}\text { Lifetime } \\
\text { prevalence }\end{array}$ & $\begin{array}{c}\text { 30 days } \\
\text { prevalence }\end{array}$ \\
\cline { 2 - 3 } & $\mathrm{n}(\%)$ & $\mathrm{n}(\%)$ \\
\hline $\begin{array}{l}\text { Alcohol, Cigarette, Khat, Shisha } \\
\text { \& Cannabis }\end{array}$ & $66(2.6)$ & $28(1.1)$ \\
Alcohol, Cigarette, Khat \& & $113(4.4)$ & $45(1.7)$ \\
Shisha & & \\
Alcohol, Cigarette, Khat \& & $83(3.2)$ & $37(1.4)$ \\
Cannabis & $195(7.6)$ & $87(3.4)$ \\
Alcohol, Cigarette \& Khat & $265(10.3)$ & $126(4.9)$ \\
Alcohol \& Cigarette & $349(13.6)$ & $167(6.5)$ \\
Alcohol \& Khat & $196(7.5)$ & $109(4.3)$ \\
Alcohol \& Shisha & $109(4.3)$ & $64(2.5)$ \\
Alcohol \& Cannabis & $126(4.9)$ & $52(2.0)$ \\
Alcohol, Cigarette \& Shisha & $97(3.8)$ & $46(1.8)$ \\
Alcohol, Cigarette \& Cannabis & &
\end{tabular}


sumed alcohol beverages. Consumption of other alcoholic beverages (7.1\%) such as local drink tej, whisky, gin and local liquor areke were also reported. Higher proportions of males compared to females reported drinking of all kinds of alcoholic beverages except wine.

Holidays (42.7\%) were the most common events/occasions for current alcohol drinkers. Drinking during the weekdays particularly in the evening (36.9\%) and on weekends (13.3\%) was also customary. In addition, $11.2 \%$ of current alcohol drinkers reported drinking alcohol regardless of a day or time as long as they have had the opportunity.

Among the current alcohol users $(n=676)$ during the last month, $84.8 \%$ drunk on 1 to 5 days, $13.6 \%$ drunk on 6 to 29 days, and $1.6 \%$ drunk on all 30 days (daily). Most students reported drinking with their friends $(42.9 \%)$, families $(41.6 \%)$ and fiancé (6.2\%). Interestingly, $0.1 \%$ students reported drinking alcohol with commercial sex workers (bar ladies) in a pub or a bar.

More than half of the students reported drinking in their friends', relatives' and own home $(52.1 \%)$ while the rest reported drinking in bars (19\%), kiosks (14\%), restaurants $(8 \%)$, other places $(7 \%)$ such as party, school, or traditional drink shop tella bet. Relaxation (75.4\%) was students' main reason for drinking alcohol followed by family/friends influence $(10 \%)$. Drinking alcohol to avoid stress $(7.2 \%)$, after chewing khat, to promote health, for experimentation, being addicted, to facilitate digestion (after having a heavy meal), and to treat minor stomach ailments especially with local liquor areke (7.4\%), were also common.

Nearly three fourth $(74.8 \%)$ of students reported that after drinking alcohol they were taking rest at home while others hang out with friends $(21.1 \%)$, smoked cigarettes $(4 \%)$, or had sexual intercourse $(3.8 \%)$. Other behaviors reported by some students $(4.4 \%)$ were crying, quarrelling with peoples, and smoking cannabis.

\subsection{Sexual Practice and Alcohol}

Among students, 412 (16.2\%) and 151 (5.9\%) reported having been engaged in sexual intercourse at least once in their lifetime and during the past month, respectively. Students' sexual experience varied with gender. More males than females reported having lifetime (26.3\% vs. $8.9 \%)$ and current (7.7\% vs. $3.4 \%)$ sexual intercourses. Unexpectedly, $12.7 \%$ of students reported having sexual intercourse at young age ( $\leq$ grade 6$)$. Among the students who had sexual intercourse at least once $(n=412)$, more than half $(52.5 \%)$ had more than one sexual partners. Almost half students (47.3\%) reported having sex without using a condom at least once in their lifetime.

Of the currently sexually active students $(n=407)$, $26.4 \%$ drunk alcohol, $7.5 \%$ chewed khat, 4.4\% smoked cigarettes, $1.8 \%$ smoked cannabis, and 1.3\% smoked shisha before a sexual intercourse.

\subsection{Determinants of Alcohol Use and Its Association with Sexual Practices}

The odds of current alcohol use were more common among students aged 18 [AOR $=2.028$; CI (1.157 $3.557)]$ or 19 years or older $[(\mathrm{AOR}=2.520$; $\mathrm{CI}$ (1.339 $4.743)$ ] than those aged $\leq 15$ years. GSS students were more likely to drink alcohol than PPS students [AOR = 1.811; CI (1.305 - 2.513)]. Getting pocket money [AOR $=1.457$; CI (1.118 - 1.898)], having shisha smoking family members [AOR = 2.259; CI (1.194 - 4.274)] or friends $[\mathrm{AOR}=1.857$; CI $(1.178$ - 2.929)], having friends who drink alcohol $[\mathrm{AOR}=1.724$; CI $(1.248$ 2.380)] were significant predictors of current alcohol use. Being current alcohol user was positively associated with current sexual practice among students $[(\mathrm{AOR}=2.260$; CI (1.282 - 3.985)].

Factors negatively associated with current alcohol use presented in Tables 3 and 4 were being Protestant Christian $[\mathrm{AOR}=0.629 ; \mathrm{CI}(0.432-0.918)$ and living with relatives/siblings $[\mathrm{AOR}=0.466$; $\mathrm{CI}(0.255-0.851)$.

\section{DISCUSSIONS}

Our study is the newest among a few studies that reported lifetime and current prevalence of alcohol drinking, multiple substance use and sexual experiences among Addis Ababa high school students. In addition, we examined the association between socio-demographic variables and current alcohol drinking practices, and alcohol use and sexual practices. Although this study has several unique features, it has also some limitations. First, we did not address binge drinking behavior; second, self reported nature the survey might result in inaccurate reporting in culturally sensitive issues such as khat use, sexual intercourse/activity or substance use. The results of the study also cannot be generalized to all adolescents since those not attending school may differ from inschool adolescents.

The prevalence of current alcohol use documented in this study was higher than other similar studies conducted in Harar province in Ethiopia, Thailand and Zimbabwe, where the current prevalence reported were between $9.5 \%$ and $12.17 \%$ [33-35]. However; the prevalence was lower than in high school students in Georgia (40\%), USA (44.9\%), Japan (44.0\%), Turkey (46\%) and Nigeria $(78.4 \%)$ [36-40]. The observed variation in prevalence estimates might be due to difference in culture, geographical location, alcohol use in general population, acceptance of alcohol use, and alcohol advertisement among the countries. Other causes of differences among studies could be related to methodology such as questionnaire used and sample selection and size. Nev- 
Table 3. Association of 30 days alcohol use and selected socio demographic characteristics of high school students in Addis Ababa, November 2010.

\begin{tabular}{|c|c|c|}
\hline \multirow{2}{*}{ Variable } & \multicolumn{2}{|c|}{30 days Alcohol use } \\
\hline & $\operatorname{COR}(95 \% \mathrm{CI})$ & $\operatorname{AOR}(95 \% \mathrm{CI})$ \\
\hline \multicolumn{3}{|c|}{ Gender } \\
\hline Male & $1.058(0.837-1.338)$ & $0.859(0.659-1.118)$ \\
\hline Female & 1.00 & 1.00 \\
\hline \multicolumn{3}{|c|}{ Age } \\
\hline$\leq 15$ & 1.00 & 1.00 \\
\hline 16 & $0.509(0.309-0.843)$ & $1.311(0.789-2.178)$ \\
\hline 17 & $0.746(0.511-1.089)$ & $1.342(0.800-2.249)$ \\
\hline 18 & $0.780(0.537-1.132)$ & $2.028^{*}(1.157-3.557)$ \\
\hline$\geq 19$ & $0.978(0.665-1.439)$ & $2.520^{*}(1.339-4.743)$ \\
\hline \multicolumn{3}{|c|}{ Religion } \\
\hline Orthodox & 1.00 & 1.00 \\
\hline Muslim & $0.893(0.521-1.528)$ & $0.720(0.375-1.379)$ \\
\hline Protestant & $0.567(0.333-0.965)$ & $0.466^{*}(0.255-0.851)$ \\
\hline Others & $0.996(0.497-1.995)$ & $1.133(0.526-2.441)$ \\
\hline \multicolumn{3}{|c|}{ Students living with } \\
\hline Two parent & 1.00 & 1.00 \\
\hline Single parent & $1.095(0.822-1.459)$ & $0.874(0.637-1.198)$ \\
\hline Relatives & $0.738(0.527-1.033)$ & $0.629^{*}(0.432-0.918)$ \\
\hline Others & $1.109(0.667-1.843)$ & $0.796(0.452-1.401)$ \\
\hline \multicolumn{3}{|c|}{ Pocket Money } \\
\hline Yes & $1.480(1.163-1.884)$ & $1.457^{*}(1.118-1.898)$ \\
\hline No & 1.00 & 1.00 \\
\hline \multicolumn{3}{|c|}{ Academic status } \\
\hline $80 \%-100 \%$ & 1.00 & 1.00 \\
\hline $60 \%-79 \%$ & $1.412(1.063-1.876)$ & $1.304(0.956-1.778)$ \\
\hline$\leq 59 \%$ & $1.922(1.129-3.271)$ & $1.610(0.904-2.865)$ \\
\hline \multicolumn{3}{|c|}{ School level } \\
\hline PPS & 1.00 & 1.00 \\
\hline GSS & $1.058(0.810-1.382))$ & $1.800^{*}(1.230-2.634)$ \\
\hline \multicolumn{3}{|c|}{ School Type ownership } \\
\hline Government & 1.00 & 1.00 \\
\hline Mission & $0.621(0.345-1.116)$ & $0.749(0.381-1.469)$ \\
\hline Private & $1.016(0.762-1.355)$ & $0.856(0.610-1.201)$ \\
\hline Public & $1.2700(.875-1.842)$ & $1.173(0.778-1.768)$ \\
\hline
\end{tabular}

${ }^{*} \mathrm{P}<0.05, \mathrm{COR}=$ Crude odds ratio; $\mathrm{AOR}=$ adjusted odds ratio; $\mathrm{CI}$, confidence interval.

ertheless, the prevalence rates of alcohol use found in this study were consistent with WHO report that indicates relatively lower alcohol consumption among African high school students [5].

Lifetime (16.2\%) and last-month (5.9\%) prevalence of sexual intercourse found in our study is difficult to com-
Table 4. Association of having substance using family and close friends with current alcohol drinking of high school students in Addis Ababa, November 2010.

\begin{tabular}{|c|c|c|c|}
\hline & & \multicolumn{2}{|c|}{30 days Alcohol use } \\
\hline & & COR $(95 \% \mathrm{CI})$ & $\operatorname{AOR}(95 \% \mathrm{CI})$ \\
\hline \multicolumn{4}{|c|}{ Alcohol drinking } \\
\hline \multirow{3}{*}{ Family } & Yes & $1.334^{*}(1.056-1.684)$ & $1.088(0.826-1.435)$ \\
\hline & No & 1.00 & 1.00 \\
\hline & & Close Friends & \\
\hline \multicolumn{2}{|c|}{ Yes } & $2.329^{*}(1.836-2.954)$ & $1.811^{*}(1.305-2.513)$ \\
\hline \multicolumn{2}{|c|}{ No } & 1.00 & 1.00 \\
\hline \multirow{4}{*}{ Family } & \multicolumn{3}{|c|}{ Cigarette smoking } \\
\hline & Yes & $1.255(0.911-1.729)$ & $1.115(0.739-1.683)$ \\
\hline & No & 1.00 & 1.00 \\
\hline & \multicolumn{3}{|c|}{ Close Friends } \\
\hline \multicolumn{2}{|c|}{ Yes } & $1.986^{*}(1.549-2.548)$ & $1.045(0.689-1.584)$ \\
\hline \multicolumn{2}{|c|}{ No } & 1.00 & 1.00 \\
\hline \multirow{4}{*}{ Family } & \multicolumn{3}{|c|}{ Khat chewing } \\
\hline & Yes & $1.172(0.893-1.538)$ & $0.753(0.520-1.091)$ \\
\hline & \multirow[t]{2}{*}{ No } & 1.00 & 1.00 \\
\hline & & \multicolumn{2}{|l|}{ Close Friends } \\
\hline \multicolumn{2}{|c|}{ Yes } & $2.167^{*}(1.696-2.769)$ & $1.017(0.672-1.539)$ \\
\hline \multicolumn{2}{|c|}{ No } & 1.00 & 1.00 \\
\hline \multirow{4}{*}{ Family } & \multicolumn{3}{|c|}{ Shisha smoking } \\
\hline & Yes & $2.508^{*}(1.547-4.067)$ & $2.259^{*}(1.194-4.274)$ \\
\hline & No & 1.00 & 1.00 \\
\hline & \multicolumn{3}{|c|}{ Close Friends } \\
\hline & & $2.657^{*}(1.998-3.534)$ & $1.857^{*}(1.178-2.929)$ \\
\hline \multicolumn{2}{|c|}{ No } & 1.00 & 1.00 \\
\hline \multirow{4}{*}{ Family } & \multicolumn{3}{|c|}{ Cannabis smoking } \\
\hline & Yes & $1.537(0.764-3.090)$ & $0.597(0.242-1.472)$ \\
\hline & No & 1.00 & 1.00 \\
\hline & \multicolumn{3}{|c|}{ Close Friends } \\
\hline & & $2.145^{*}(1.533-3.000)$ & $1.090(0.656-1.809)$ \\
\hline & & 1.00 & 1.00 \\
\hline
\end{tabular}

${ }^{*} \mathrm{P}<0.05, \mathrm{COR}=$ Crude odds ratio; $\mathrm{AOR}=$ adjusted odds ratio; $\mathrm{CI}$, confidence interval.

pare with other reports from African countries since not many studies have been reported. In a study conducted in Zambia, past year prevalence rate of sexual intercourse among in-school adolescents was. 13.4\% [41] which is comparable to our findings between with. The difference could be due to the variation in the interval of data collection period. In our study we asked for both, lifetime and 30 days recall period while study in Zambia used one year recall period. Cultural variation between two countries may also explain the difference in prevalence. 
In this study we found an association initiation of alcohol drinking with sexual practices. Majority of students started drinking alcohol and practicing sexual intercourse at early age while attending GSS school (42.9\% began drinking alcohol and $46.2 \%$ began sexual intercourse) and JSS (35.7\% began drinking alcohol and $31.3 \%$ began sexual intercourse). According to the Ministry of Education of Ethiopia [42], the average age for alcohol drinking initiation for GSS and JSS students is 15 to 16 and 13 to 14 years, respectively. These ages are close to alcohol initiation age reported in Japan i.e. 13 years [37] but lower compared to high school students in Harar, Ethiopia (17.5 years) [33]. Wide cultural acceptance and availability of home brewed alcoholic beverages particularly during holidays might contribute for early alcohol exposure to sizable proportion of students. Studies also showed that early initiation of alcohol drinking and sexual exposure, and substance use prior to sexual intercourse and are likely cause of unintended pregnancy. Other consequences include involvement in risky sexual behavior such as unprotected vaginal sex, having multiple sexual partners, and increased risk for sexually transmitted disease including HIV/AIDS. Such risky behaviors might often continue through mid-adolescence and later $[9,11,18]$.

We found that as reported in other studies [40,43], relaxation, influence of friends and family were the major motives for alcohol drinking. The common alcohol drinking after khat chewing often reported in this study might have reduced stimulation caused by cathinone from khat and allowed falling asleep especially at night. Similar behavior was reported by other studies $[44,45]$.

The current alcohol drinking practice in all students was strongly associated with getting pocket money, and having close friends and family who are current substances users. Previous studies conducted in various settings also reported similar findings $[35,46,47]$.

The GSS students were twice more likely than PPS students to be current alcohol drinkers. The transition from JSS to GSS usually requires attending a new school (especially in government-run school system) and adaptation to a new environment. These factors change might also contribute to either initiation of alcohol use or become a current alcohol drinker [48]. Maturity of students may have protective effect for PPS. Interesting finding that protestant faith followers were less likely to be current alcohol drinkers compared to orthodox Christians require further studies. Perhaps religions with more conservative view about alcohol use may have protective effect against risky behaviors as reported earlier [49].

\section{CONCLUSION}

Alcohol drinking among high school students in Addis Ababa is a major public health concern with lifetime and current prevalence of $45.7 \%$ and $26.5 \%$, respectively. High-risk sexual behavior such as not using a condom, multiple sexual partners and substance use prior to sexual intercourse was also common. Current alcohol drinking was associated with age, religion, living with (cohabiting) type, school level, pocket money and having family and close friends who use substances. Educating the adverse outcomes of alcohol drinking and other substances through Medias and in schools curriculum is recommended. In addition, expanding safe recreational place, engaging students in extracurricular activity and regulating the sale of alcohol for the underage would be beneficial to minimize the risk of alcohol drinking.

\section{ACKNOWLEDGEMENTS}

We would like to kindly acknowledge the study participants in Addis Ababa High school who enthusiastically participated in this study for their time and for sharing us their experiences. We also extend our appreciation to school directors, and counseling and guidance office for facilitating the session. Financial and material support for the study was made available by the School of Pharmacy, Addis Ababa University, Addis Ababa University MARCH Project and AIDS Resource Center.

\section{REFERENCES}

[1] Fatusi, A.O. and Hindin, M.J. (2010) Adolescents and youth in developing countries: Health and development issues in context. Journal of Adolescence, 33, 499-508. doi:10.1016/j.adolescence.2010.05.019

[2] WHO (2011) Adolescent health. http://www.who.int/topics/adolescent health/en/

[3] McCarthy, W.J., Mistry, R., Lu, Y., Patel, M., Zheng, H. and Dietsch, B. (2009) Density of tobacco retailers near schools: effects on tobacco use among students. American Journal of Public Health, 99, 2006-2013. doi:10.2105/AJPH.2008.145128

[4] DuRant, R.H., Smith, J.A., Kreiter, S.R. and Krowchuk, D.P. (1999) The relationship between early age of onset of initial substance use and engaging in multiple health risk behaviors among young adolescents. Archives of Pediatrics \& Adolescent Medicine, 153, 286-291. doi:10.1001/archpedi.153.3.286

[5] WHO (2011) Global status report on alcohol and health. World Health Organization, Geneva.

[6] Garretsen, H.F., Bongers, I.M., van Oers, J.A. and van de Goor, L.A. (1999) The development of alcohol consumption and problem drinking in Rotterdam 1980-1994: More problem drinking amongst the young and the middle aged. Alcohol, 34, 733-40. doi:10.1093/alcalc/34.5.733

[7] Kim, J.H., Lee, S., Chow, J., Lau, J., Tsang, A., Choi, J. and Griffiths, S.M. (2008) Prevalence and the factors associated with binge drinking, alcohol abuse, and alcohol dependence: A population-based study of Chinese adults in Hong Kong. Alcohol, 43, 360-370. doi:10.1093/alcalc/agm181 
[8] Donovan, J.E. (2005) Problem behaviour theory. In: Flisher, C.B. and Lerner, R.M. Eds., Encyclopedia of Applied Development Science. 2nd Edition, Thousand Oaks, Sage, 872-877.

[9] Bellis, M.A., Hughes, K., Calafat, A., Juan, M., Ramon, A., Rodriguez, J.A., Mendes, F., Schnitzer, S. and Phillips-Howard, P. (2008) Sexual uses of alcohol and drugs and the associated health risks: A cross sectional study of young people in nine European cities. BMC Public Health, 8, 155. doi:10.1186/1471-2458-8-155

[10] Best, D., Rawaf, S., Rowley, J., Floyd, K., Manning, V. and Strang, J. (2000) Drinking and smoking as concurrent predictors of illicit drug use and positive drug attitudes in adolescents. Drug and Alcohol Dependence, 60, 319-321. doi:10.1016/S0376-8716(00)00113-7

[11] Stueve, A. and O'Donnell, L.N. (2005) Early alcohol initiation and subsequent sexual and alcohol risk behaviors among urban youths. American Journal of Public Health, 95, 887-893. doi:10.2105/AJPH.2003.026567

[12] NIDA (2010) The science of addiction-Drugs, brains and behaviours. NIH Pub No. 10-5605.

[13] Martin, J., Barry, J. and Skally, M. (2011) Alcohol attributable hospitalisations and costs in Ireland, 2000-2004. Irish Medical Journal, 104, 140-144.

[14] Fekadu, A., Alena, A. and Hanlon, C. (2007) Alcohol and drug abuse in Ethiopia: Past, present and future. African Journal of Drug \& Alcohol Studies, 6, 39-53.

[15] Kassaye, M., Sherief, H., Fissehaye, G. and Teklu, T. (1999) "Drug" use among high school students in Addis Ababa and Butajira. Ethiopian Journal of Health Development, 13, 101-106.

[16] Carter, M., McGee, R., Taylor, B. and Williams, S. (2007) Health outcomes in adolescence: associations with family, friends and school engagement. Journal of Adolescent Health, 30, 51-62. doi:10.1016/j.adolescence.2005.04.002

[17] Bishop, D.I., Weisgram, E.S., Holleque, K.M., Lund, K.E. and Wheeler-Anderson, J.R. (2005) Identity development and alcohol consumption: Current and retrospective selfreports by college students. Journal of Adolescent Health, 28, 523-533. doi:10.1016/i.adolescence.2004.10.007

[18] Sychareun, V., Thomsen, S., Faxelid, E. (2011) Concurrent multiple health risk behaviors among adolescents in Luangnamtha province, Lao PDR. BMC Public Health, 11, 1-10. doi:10.1186/1471-2458-11-36

[19] Poelen, E.A.P., Scholte, R.H.J., Engels, R.C.M.E., Boomsmab, D.I. and Willemsen, G. (2005) Prevalence and trends of alcohol use and misuse among adolescents and young adults in the Netherlands from 1993 to 2000. Drug \& Alcohol Dependence, 79, 413-421. doi:10.1016/j.drugalcdep.2005.03.020

[20] Ahlström, S.K. and Österberg, E.L. (2005) International perspectives on adolescent and young adult drinking. Alcohol Research and Health, 28, 258-268. doi:10.1186/1471-2458-12-527

[21] Bennett, L.A., Campillo, C., Chandrashekar, C.R. and Gureje, O. (1998) Alcoholic beverage consumption in India, Mexico, and Nigeria: A cross-cultural comparison. Alcohol Health and Research World, 22, 243-252.
[22] Benjet, C., Borges, G., Medina-Mora, M.E., Blanco, J., Zambrano, J., Orozco, R., et al. (2007) Drug use opportunities and the transition to drug use among adolescents from the Mexico City Metropolitan Area. Drug \& Alcohol Dependence, 90, 128-134. doi:10.1016/j.drugalcdep.2007.02.018

[23] Andersen, A., Holstein, B.E. and Due, P. (2007) Schoolrelated risk factors for drunkenness among adolescents: Risk factors differ between socio-economic groups. European Journal of Public Health, 17, 27-32. doi:10.1093/eurpub/ck1071

[24] Hung, C.C., Yen, L.L. and Wu, W.C. (2009) Association of parents' alcohol use and family interaction with the initiation of alcohol use by sixth graders: A preliminary study in Taiwan. BMC Public Health, 9, 172. doi:10.1186/1471-2458-9-172

[25] Fothergill, K.E. and Ensminger, M.E. (2006) Childhood and adolescent antecedents of drug and alcohol problems: A longitudinal study. Drug \& Alcohol Dependence, 82, 61-76. doi:10.1016/j.drugalcdep.2005.08.009

[26] Brooks, F.M., Magnusson, J., Spencer, N. and Morgan, A. (2012) Adolescent multiple risk behaviour: An asset approach to the role of family, school and community. Journal of Public Health (Oxford), 34, i48-i56. doi:10.1093/pubmed/fds001

[27] Becerra, D. and Castillo, J. (2011) Culturally protective parenting practices against substance use among adolescents in Mexico. Journal of Substance Use, 16, 136-149. doi:10.3109/14659891.2010.518199

[28] CSA (2012) Ethiopia statical annual abstarct 2011. http://www.csa.gov.et/index.php?option=com rubberdoc \&view $=$ doc\&id=421\& format $=$ raw \&Itemid $=606$

[29] Central Statistical Agency of Ethiopia (2008) Summary and statistical report of the 2007 population and housing census: Population size by age and sex. Federal Democratic Republic of Ethiopia Population Census Commission.

[30] Addis Ababa Education Bureau (2010) Education statistics annual abstract 2008/09. Addis Ababa: Educational management information system (EMIS) - Study, plan and budget support process city government.

[31] ESPAD (2008) Methodology. http://www.espad.org/methodology

[32] Berhane, Y. and Worku, A. (2007) Alcohol and Khat consumption and the association with HIV/AIDS prevention, care and treatment in Ethiopia: Final report. Addis Continental Institute of Public Health.

[33] Reda, A., Moges, A., Wondmagegn, B. and Biadgilign, S. (2012) Alcohol drinking patterns among high school students in Ethiopia: A cross-sectional study. BMC Public Health, 12, 1-6. doi:10.1186/1471-2458-12-213

[34] Rudatsikira, E., Maposa, D., Mukandavire, Z., Muula, A.S. and Siziya, S. (2009) Prevalence and predictors of illicit drug use among school-going adolescents in Harare, Zimbabwe. Annals of African Medicine, 8, 215-220. doi:10.4103/1596-3519.59574

[35] Chaveepojnkamjorn, W. and Pichainarong, N. (2011) Current drinking and health-risk behaviors among male 
high school students in central Thailand. BMC Public Health, 11, 233. doi:10.1186/1471-2458-11-233

[36] Sturua, L., Baramidze, L., Gamkrelidze, A. and Galdava, G. (2010) Alcohol use in Georgian students; pilot study rigorously following criteria of European school project on alcohol and other drug. Georgian Medical News, 179, 52-61.

[37] Shimane, T. and Wada, K. (2007) Substance use among night high school students in Japan. Nihon Arukoru Yakubutsu Igakkai Zasshi, 42, 152-164.

[38] Miller, J.W., Naimi, T.S., Brewer, R.D. and Jones, S.E. (2007) Binge drinking and associated health risk behaveiors among high school students. Pediatrics, 119, 76-85. doi:10.1542/peds.2006-1517

[39] Alikasifoglu, M., Erginoz, E., Ercan, O., Uysal, O., Albayrak-Kaymak, D. and Ilter, O. (2004) Alcohol drinking behaviors among Turkish high school students. The Turkish Journal of Pediatrics, 46, 44-53.

[40] Chikere, E.I. and Mayowa, M.O. (2011) Prevalence and perceived health effect of alcohol use among male undergraduate students in Owerri, South-East Nigeria: A descriptive cross-sectional study. BMC Public Health, 11, 118. doi:10.1186/1471-2458-11-118

[41] Siziya, S., Muula, A.S., Kazembe, L.N. and Rudatsikira, E. (2008) Harmful lifestyles' clustering among sexually active in-school adolescents in Zambia. BMC Pediatrics, 8, 6. doi:10.1186/1471-2431-8-6

[42] Minstry of Education (MoE) (2009) Ethiopia-education system. http://www.ethiopia.gov.et/English/MOE/Information/Pa ges/Fact $\% 20$ Sheets.aspx
[43] Madu, S.N. and Matla, M.Q. (2003) Illicit drug use, cigarette smoking and alcohol drinking behaviour among a sample of high school adolescents in the Pietersburg area of the Northern Province, South Africa. Journal of Adolescence, 26, 121-136. doi:10.1016/S0140-1971(02)00120-3

[44] Ihunwo, A.O., Kayanja, F.I. and Amadi-Ihunwo, U.B. (2004) Use and perception of the psychostimulant, khat (Catha edulis) among three occupational groups in south western Uganda. East African Medical Journal, 81, 468473. doi:10.4314/eamj.v81i9.9223

[45] Gelaw, Y. and Haile-Amlak, A. (2004) Khat chewing and its socio-demographic correlates among the staff of Jimma University. Ethiopian Journal of Health Development, 18, 179-184.

[46] Rudatsikira, E., Dondog, J., Siziya, S. and Muula, A.S. (2008) Prevalence and determinants of adolescent cigarette smoking in Mongolia. Singapore Medical Journal, 49, 57-62.

[47] Denny, S.J., Robinson, E.M., Utter, J., Fleming, T.M., Grant, S., Milfont, T.L., et al. (2011) Do schools influence student risk-taking behaviors and emotional health symptoms? Journal of Adolescent Health, 48, 259-267. doi:10.1016/j.jadohealth.2010.06.020

[48] Brian, K.B. and Joseph, A.O. (2004) Assessing the transitions to middle and high school. Journal of Adolescent Research, 19, 3-30. doi:10.1177/0743558403258113

[49] Gnadt, B. (2006) Religiousness, current substance use, and early risk Indicators for substance abuse in nursing students. Journal of Addictions Nursing, 17, 151-158. doi: $10.1080 / 10884600600862103$ 